18. Смирнов Е.И. Фундирование опыта в профессиональной подготовке и инновационной деятельности педагога. Ярославль: Канцлер, 2012. 677 с.

19. Примерная основная образовательная программа основного общего образования [Электронный pecypc] // http://fgosreestr.ru/registry/primernaya-

\title{
INTER-SUBJECT LINKS WITHIN THE CONTENT-METHODICAL LINES OF MATH SCHOOL COURSE
}

(C) 2019

Kononenko Natalya Vasilievna, candidate of pedagogical sciences, associate professor of Fundamental and Applied Mathematics, Theory and Methods of Teaching Mathematics Department

Tokareva Julia Sergeevna, candidate of physical and mathematical sciences, dean of Natural Sciences, Mathematics and Technology Faculty

Transbaikal State University (Chita, Russian Federation)

Chukhriy Pavel Aleksandrovich, teacher of mathematics Secondary School № 48 (Chita, Russian Federation)

Abstract. This paper considers some ways of inter-subject links realization within the content-methodical lines of Math school course. The course of Math at school is permeated with inter-subject links, which are the foundation of the subject and through which a succession is implemented in teaching of Mathematics. The implementation of intersubject links in teaching Mathematics requires a special organization of educational material and the process of its study and, therefore, acts as a didactic principle. In this paper, inter-subject links are revealed at two levels: the level of content and the level of methods for solving problems. The inter-subject links at the substantial level are learning numerical sequences and linear equations and inequalities, while at the level of methods - examples of transcendental equations. The implementation of inter-subject links at the content level takes place in conjunction with their implementation at the level of methods and has a wide practical application at Mathematics lessons. The conducted researches have shown that inter-subject links naturally extend on the subject area «Mathematics and Computer Science» according to the Federal state educational standards of the basic and secondary general education. The practical significance of the study is that its results can be used for teaching Mathematics at school.

Keywords: inter-subject links; mathematics; content-methodical line; mathematics education; learning process; methodology of teaching; mathematical concepts; linear equation; numerical consistency; quadratic equation; level of maintenance; level of problem-solving techniques.

\section{СОВРЕМЕННЫЕ ФОРМАТЫ МЕТОДИЧЕСКОЙ ПОДГОТОВКИ СТУДЕНТОВ-БИОЛОГОВ} (C) 2019

Митина Елена Гарисоновна, доктор педагогических наук, доцент, профессор кафедры естественных наук

Крыштоп Виктория Анатольевна, кандидат педагогических наук, доцент кафедры естественных наук Мурманский арктический государственный университет (г. Мурманск, Российская Федерация)

Аннотащия. Статья посвящена изучению отношения студентов, как будущих педагогов, к процессу методической подготовки в вузе. Авторами дана характеристика некоторых примеров «форматирования» методической подготовки студентов-биологов, таких как «форма обучения», «образовательный формат», «формат обучения» и другие. Авторы представили результаты анализа проведенного опроса студентов о предпочтениях в выборе того или иного формата; определены принципы включения новых форматов в процесс обучения в высшем учебном заведении. В статье показано, что на современном этапе наиболее востребованы студентами форматы методической подготовки, основанные на непосредственном взаимодействии всех субъектов образовательного процесса, в то время как форматы обучения в интернет-пространстве являются менее привлекательными для респондентов. Авторами статьи, на основании изучения мнения студентов, установлено, что содействие развитию других субъектов учебного процесса и постоянное повышение их квалификации наиболее важны для успешного «форматирования» методической подготовки педагогабиолога. Представленные авторами в данной публикации принципы включения новых форматов в процесс обучения ориентируют его на расширение границ образовательных систем в соответствии с современными тенденциями развития образования, отмеченными в новых образовательных стандартах.

Ключевые слова: форма организации обучения; формат обучения; организационные формы и методы обучения; профессиональная подготовка педагогов; методическая подготовка; модули методической подготовки; образовательная среда; принципы включения форматов; реализация современных форматов; интернетпространство. 
Современное образование развивается в разных направлениях и характеризуется рядом тенденций, в том числе переходом к личностно-ориентированной парадигме, индивидуализации обучения, открытости образовательных систем. Сегодня развитию этих тенденций постепенно и целенаправленно подчиняются отбор содержания образования, организационные формы и методы обучения. В связи с этим особую актуальность приобретает осмысление новых форм обучения, которые все более активно проникают в современное образование [1].

С философской точки зрения форма - внешнее отражение содержания, в образовании - способ реализации педагогического процесса, осуществляемого образовательными учреждениями в системе формального образования, который имеет организованный и иерархически структурированный контекст и четко определенные временные границы [2]. Системы форм организации обучения подробно описаны в педагогической литературе, однако в настоящее время вместе с устоявшимися понятиями «форма организации обучения» и «форма обучения» все чаще употребляется термины «образовательный формат», «формат обучения». Слово «формат» имеет в словарях различное толкование и чаще всего применяется для описания структурных характеристик того или иного явления, процесса или объекта: например, формат листа, формат записи информации, формат общения, формат мероприятия, формат встречи и т.д. [3]. Сегодня проводится всемирное обсуждение будущих форматов образования - Global Education Future в условиях становления сетецентрического общества. При этом жесткие временные рамки и иерархическая организация обучения, структурированное содержание не отвечают потребностям такого общества. В связи с этим «форматирование» образования сегодня становится необходимым, и форматы как способы организации коммуникации, сотрудничества и обратной связи в аудитории становятся все более востребованными. Понятия «образовательный формат», «формат обучения» пока еще недостаточно охарактеризованы в педагогической литературе, в то время как уже накоплен значительный материал о форматах, которые применяются в условиях открытости и развития новых типов образовательных систем.

Анализ публикаций последних лет по данной теме в системе РИНЦ показал, что сегодня идет активное описание разнообразных форматов, применяемых в современной образовательной практике, в том числе в подготовке педагогов. Приведем некоторые примеры: образовательный коворкинг, культурнообразовательные практики, формат дистанционного экзамена, компетентностный формат образовательных стандартов, компетентностный формат обучения, формат образовательного события, выставка как образовательный формат, хакатон - формат проектной деятельности, сетевой формат, формат летних школ, формат образовательной ситуации, детский технопарк как образовательный формат, коммуникативный формат обучения и т.д. При этом часто к описанию того или иного формата применяется слово «новый», а такое многообразие описываемых форматов говорит о вариативности содержания и видов деятельности внутри того или иного формата, открытости и логики их границ, незаданности ре- зультатов, что соответствует современному пониманию нелинейности образовательных систем [4; 5]. Особое значение развития новых форматов обучения приобретает цифровизация образовании, которая сегодня становится педагогической действительностью, и ее потенциал необходимо и возможно использовать для формирования навыков и компетенций человека будущего. Уже сегодня предлагаются и активно наполняются ресурсами открытые образовательные платформы, онлайн-курсы, виртуальная и дополненная реальность, обучающие игры, которые должны, вне всяких сомнений, найти свое место в методической подготовке студентов. Вместе с этим существуют ряд рисков цифровизации методической подготовки, в том числе потеря субъектности, которая крайне важна для приобретения методического опыта в процессе общения с преподавателем.

В настоящее время наблюдается острейшее противоречие между постоянно возрастающими требованиями к выпускнику педагогического вуза и условиями его подготовки. В первую очередь это касается психолого-педагогической подготовки будущих учителей, а также организации и проведения педагогической практики [6]. Среди проблем подготовки устаревшие методы и технологии, отсутствие достаточного количества часов на практику и стажировку, отсутствие деятельностного подхода в подготовке студентов [7]. Однако среди основных организационно-педагогических условий формирования и развития профессиональной компетентности студентов выделяют организационно-управленческие и учебнометодические, среди которых - не только реализация основных теорий и концепций педагогического образования, но и овладение опытом осуществления будущей профессиональной деятельности на практике [8, с. 28]. Профессиональная педагогическая подготовка студентов, в том числе и методическая, в этих условиях приобретает новый ориентир: от подготовки студентов к «обучению школьников предмету к обучению предметом». Биология как учебный предмет в этом смысле обладает широкими возможностями и является активно развивающимся учебным предметом.

Изучению процесса методической подготовки студентов посвящены исследования Н.Д. Андреевой, И.Ю. Азизовой, П.В. Скулова и других [9-14]. К функциям методической подготовки относятся: формирование типичных видов профессионально-методической деятельности и обобщенных способов их осуществления, а также развитие способностей выбирать и применять инвариантные решения по технологии выполнения преподавательских действий. Реализация этих функций возлагается на целостный процесс методической подготовки учителей-предметников [15, с. 106]. В этих условиях перед преподавателями методических дисциплин в вузе ставится «двоякая задача»: с одной стороны - эффективно использовать возможности различных форматов методической подготовки студентов. С другой - сориентировать будущих педагогов-биологов в возможностях форматов современного биологического образования и их применимости в различных образовательных средах.

Все эти обстоятельства востребуют потенциал новых форматов методической подготовки, расши- 
Митина Е.Г., Крыштоп В.А.

рения границ организационных форм обучения студентов, гибкости и вариативности содержания [1620]. Приведем некоторые примеры краткого описания таких форматов и их применения в практике методической подготовки студентов-биологов.

Совместная работа в пространстве, которое имеет все необходимые условия и современное оборудование, предназначенное для образовательной и научноисследовательской деятельности. В качестве таких пространств могут выступать открытые учебные площадки: ботанические сады, океанариумы, музеи и пр. Открытые учебные площадки предоставляют широкие возможности для совместной работы специалистов, педагогов и студентов: выполнение учебных проектов и исследовательских работ, самостоятельное освоение студентами модулей методической и т.д. [3]. Структура такого формата методической подготовки включает запрос сторон, создание условий для взаимодействия, технологию совместных действий в процессе решения поставленных задач и продукт. Необходимость привлечения таких форматов в процесс обучения студентов обусловлена требованиями ФГОС ВО всех уровней направления подготовки «Педагогическое образование» в части не только методической, но и культурно-просветительской деятельности, участие и организация в которой так же требуют определенных методических знаний и умений от педагога [3].

«Мастерская наставников» как современный формат обучения студентов предполагает разработку проектов под руководством приглашенных специалистов. В качестве таких проектов в условиях методической подготовки студентов-биологов могут выступать разработка кейс-заданий для системы дополнительного биологического образования, - например, для сети детских технопарков «Кванториум» [3].

Проектная сессия - интенсивный тип обсуждения, который позволяет продвинуть проект вперёд. Например, создание коллективной монографии «Биологическое образование в современном мире». Студенты, работая в группе, создают совместный «продукт», включающий все необходимые компоненты коллективной монографии: введение, разделы, описывающие биологическое образование в разных странах и их сравнительную характеристику по заданным признакам и заключение. Создание такой монографии требует интенсивного обсуждения хода работы над проектом, и проектная сессия позволяет продвигать студентов по пути его создания.

Эти примеры далеко не исчерпывают список современных форматов, применимых в методической подготовке студентов. Однако условно среди них мы можем выделить форматы, связанные с информатизацией и технологизацией современного образования. Например, исследовательская работа «Формирование общепрофессиональных компетенций бакалавров биологии в условиях цифровой лаборатории ПАСКО» позволила включить магистранта в процесс профессиональной подготовки студентов и создать предпосылки для формирования методических умений: целеполагания отбора содержания овладения методами контроля и оценки знаний применения интерактивных средств обучения. Овладев умениями работы с цифровым оборудованием, студент выступил в качестве наставника для студентов младших курсов бакалавриата. Проект под названием «Исследователь Арктики» на дистанционной образовательной платформе «Stepic» может стать форматом обучения школьников студентов и педагогов с помощью дистанционных технологий и учебной площадкой методической подготовки в виртуальном пространстве.

Другой современный формат - интернет-серфинг (веб-серфинг) представляет собой самостоятельный информационный поиск в сети на заданную тему из разных источников: специализированных сайтов, электронных библиотек, форумов, открытых лекций и пр. В условиях данного формата создаются условия для развития у студентов навыков поиска и обработки информации об изучаемом объекте, предмете, процессе или явлении [3]. Применение данного формата актуально для изучения современного состояния биологического образования в мире, ознакомления с новыми результатами исследований методической науки. В качестве примера задания для проведения интернет-серфинга можно привести составление тематического портфолио на тему «Проблема отбора содержания биологического образования в условиях модернизации». В рамках выполнения портфолио студенты собирают и различными способами обрабатывают собранную информацию: составляют опорный конспект и аннотируют статей, формулируют тезисы научных публикаций, проводят опрос общественного мнения, берут интервью у эксперта [3].

Таким образом, все эти форматы методической подготовки можно считать определенными способами коммуникации в сообществах «студент - преподаватель» «студент - студент» «студент - учитель».

Для выявления предпочтений студентов в выборе современных форматов методической подготовки был проведен опрос среди 25 студентов-магистрантов, обучающихся по направлению подготовки «Педагогическое образование», профили «Биологическое образование» «Биолого-химическое образование» Мурманского арктического государственного университета, Российского государственного педагогического университета им. А.И. Герцена. Результаты представлены в таблице 1 .

Таблица 1 - Предпочтения студентов-биологов в выборе современных форматов методической подготовки (уровень магистратуры)

\begin{tabular}{|l|c|c|}
\hline Форматы методической подготовки & $\begin{array}{c}\text { Кол- } \\
\text { во }\end{array}$ & $\begin{array}{c}\text { Доля, } \\
\%\end{array}$ \\
\hline $\begin{array}{l}\text { Совместная (проектная) работа } \\
\text { со специалистами }\end{array}$ & 18 & 72 \\
\hline Интернет-серфинг & 9 & 36 \\
\hline Формат WIКI & 6 & 24 \\
\hline $\begin{array}{l}\text { Индивидуальная работа } \\
\text { п педагогом-наставником }\end{array}$ & 15 & 60 \\
\hline Вебинар & 2 & 8 \\
\hline Видеолекция & 3 & 12 \\
\hline $\begin{array}{l}\text { Аудиторный тренинг } \\
\text { методический практикум) }\end{array}$ & 11 & 44 \\
\hline $\begin{array}{l}\text { Дистанционные обучающие модули } \\
\text { с тестированием и самопроверкой }\end{array}$ & 7 & 28 \\
\hline Проектная сессия & 5 & 20 \\
\hline
\end{tabular}


Митина Е.Г., Крыштоп В.А.

Современные форматы методической подготовки студентов-биологов

Педагогические науки

Анализ результатов опроса студентов показал, что наиболее востребованы те форматы методической подготовки, в рамках которых происходит непосредственное взаимодействие субъектов образовательного процесса (проектная работа, индивидуальная работа, аудиторный тренинг). Менее привлекательны для них форматы в интернет-пространстве, при этом, по мнению будущих педагогов-биологов, интернет-серфинг и дистанционное обучение из предлагаемых форматов наиболее приемлемы для методической подготовки. Результаты опроса представлены в табл. 2.

Таблица 2 - Предпочтения студентов гуманитарного направления подготовки в выборе современных форматов обучения (уровень бакалавриата)

\begin{tabular}{|l|c|c|}
\hline Форматы методической подготовки & $\begin{array}{c}\text { Кол- } \\
\text { во }\end{array}$ & $\begin{array}{c}\text { Доля, } \\
\%\end{array}$ \\
\hline $\begin{array}{l}\text { Совместная (проектная) работа } \\
\text { со специалистами }\end{array}$ & 17 & 68 \\
\hline Интернет-серфинг & 8 & 32 \\
\hline Формат WIKI & 7 & 28 \\
\hline $\begin{array}{l}\text { Индивидуальная работа } \\
\text { с педагогом-наставником }\end{array}$ & 12 & 48 \\
\hline Вебинар & 5 & 20 \\
\hline Видеолекция & 5 & 20 \\
\hline $\begin{array}{l}\text { Аудиторный тренинг } \\
\text { (методический практикум) }\end{array}$ & 10 & 40 \\
\hline $\begin{array}{l}\text { Дистанционные обучающие модули } \\
\text { с тестированием и самопроверкой }\end{array}$ & 10 & 40 \\
\hline Проектная сессия & 7 & 28 \\
\hline
\end{tabular}

Бакалавры гуманитарного профиля направления подготовки «Педагогическое образование» оказались солидарны в выборе предпочтений форматов обучении с магистрантами: (проектная работа, индивидуальная работа, аудиторный тренинг и добавилось дистанционное обучение). Так же для них менее привлекательны такие форматы, как: интернет-серфинг и вики, но при этомони более предпочтительны, чем видеолекции и вебинар).

В ходе следующего опроса магистранты обозначили свое видение качеств, необходимых педагогу высшей школы для успешного включения форматов в методическую подготовку будущего учителя-предметника. Результаты опроса представлены в табл. 3.

Таблица 3 - Качества преподавателя, необходимые для необходимые для успешной реализации современных форматов методической подготовки (уровень магистратуры)

\begin{tabular}{|l|c|c|}
\hline \multicolumn{1}{|c|}{ Качества преподавателя } & $\begin{array}{c}\text { Кол- } \\
\text { во }\end{array}$ & $\begin{array}{c}\text { Доля, } \\
\%\end{array}$ \\
\hline $\begin{array}{l}\text { Готов содействовать } \\
\text { развитию других }\end{array}$ & 21 & 84 \\
\hline Много читает по специальности & 18 & 72 \\
\hline $\begin{array}{l}\text { Регулярно публикует результаты } \\
\text { своей работы }\end{array}$ & 6 & 24 \\
\hline Пользуется авторитетом у коллег & 2 & 8 \\
\hline Регулярно обучается нововведениям & 21 & 84 \\
\hline Руководством назначен экспертом & 1 & 4 \\
\hline
\end{tabular}

По результатам анализа ответов этой группы студентов можно утверждать, что содействие развитию других и постоянное повышение квалификации (обу- чение нововведениям) наиболее важны, по мнению студентов, для успешного применения преподавателем вышеуказанных форматов в процессе методической подготовки педагога-биолога. Менее значима публикационная активность преподавателя, авторитет среди коллег и назначения руководства.

По мнению студентов-бакалавров, самые важные качества преподавателя также содействие развитию других, обучение, чтение специальной литературы. По сравнению с магистрантами больше доверяют руководству. Результаты опроса представлены в табл. 4.

Таблица 4 - Качества преподавателя, необходимые для успешной реализации современных форматов методической подготовки (уровень бакалавриата)

\begin{tabular}{|l|c|c|}
\hline \multicolumn{1}{|c|}{ Качества преподавателя } & $\begin{array}{c}\text { Кол- } \\
\text { во }\end{array}$ & $\begin{array}{c}\text { Доля, } \\
\%\end{array}$ \\
\hline $\begin{array}{l}\text { Готов содействовать } \\
\text { развитию других }\end{array}$ & 20 & 80 \\
\hline Много читает по специальности & 15 & 60 \\
\hline $\begin{array}{l}\text { Регулярно публикует результаты } \\
\text { своей работы }\end{array}$ & 3 & 12 \\
\hline Пользуется авторитетом у коллег & 3 & 12 \\
\hline Регулярно обучается нововведениям & 20 & 80 \\
\hline Руководством назначен экспертом & 6 & 24 \\
\hline
\end{tabular}

Результаты анкетирования студентов позволяют обозначить запрос «педагога будущего» на целый спектр компетенций преподавателя методических дисциплин в вузе: предметных, управленческих, коммуникативных, познавательных и информационных. Проблема подготовки такого педагога приобретает сегодня особую остроту и требует своего решения.

Таким образом, в настоящее время в условиях информатизации, стандартизации и технологизации современного образования происходит становление новых образовательных форматов обучения. Включение таких форматов в процесс методической подготовки студентов обогатит его новыми возможностями, позволит актуализировать тенденции развития образования в обучении будущих педагоговбиологов [3].

\section{Список литературы:}

1. Примерные основные образовательные программы по направлению подготовки 44.03.01 Педагогическое образование, направленность (профиль) «Биологическое образование», уровень высшего образования - бакалавриат и 44.04.01 Педагогическое образование, направленность (профиль) «Биологическое образование», уровень высшего образования магистратура. СПб.: Изд-во РГПУ им. А.И. Герцена, 2017. 127 c.

2. Ситаров В.А. Дидактика: учеб. пособие для студ. высш. пед. учеб. заведений / под ред. В.А. Сластенина. 2-е изд., стереотип. М.: Издательский центр «Академия», 2004. 368 с.

3. Митина Е.Г. Современные форматы обучения в методической подготовке студентов-биологов // Биологическое и экологическое образование в школе и вузе: теория, методика, практика: сборник статей междунар. науч.-практ. конф. (14-17 ноября 2017 г.). Вып. 15 (2), Санкт-Петербург / под ред. проф. Н.Д. Андреевой. СПб.: Свое издательство, 2017. С. $180-182$. 
4. Капцов А.В., Колесникова Е.А. Становление субъективности студентов в вузе в аспекте компетентностного подхода // Вестник Самарской гуманитарной академии. Серия: Психология. 2018. № 1 (23). C. $16-33$.

5. Селезнева М.В. Исследование субъективности преподавателя вуза с позиций эффективности его образовательной деятельности // Личностно-профессиональное и карьерное развитие: актуальные исследования и форсайт-проекты: мат-лы науч.-практ. конф. / под ред. Л.М. Митиной. М.: Издательство «Перо», 2018. С. 240-244.

6. Пасечник В.В. Проблемы подготовки учителей биологии в условиях модернизации отечественного образования // Профессионализм педагога: сущность, содержание, перспективы развития: мат-лы междунар. науч.-практ. конф., посв. 130-летию со дня рожд. А.С. Макаренко. 15-16 марта 2018 г., Москва, МГОУ / под ред. Е.И. Артамоновой. В 2 ч. Ч. 2. М.: МАНПО, 2018. С. 260-264.

7. Концепция поддержки развития педагогического образования [Электронный ресурс] // http:// минобрнауки.рф/пресс-центр/3875.

8. Недюрмагомедов Г.Г., Вагабова Н.Я., Исаева П.И. Формирование профессиональной компетенции у будущего учителя биологии // XXVIII Ершовские чтения: сб. науч. ст. / отв. ред. С.А. Еланцева. Ишим: Изд-во ИПИ им. П.П. Ершова (филиал) ТюмГУ, 2018. С. 26-28.

9. Андреева Н.Д. Когнитивный компонент исследовательской деятельности студентов-биологов // Вестник ПГУ. 2018. № 3. С. 41-48.

10. Азизова И.Ю. Система методической подготовки студентов-биологов в условиях гуманитаризации и технологизации высшего педагогического образования: монография. СПб.: Изд-во «Свое издательство», 2015. 149 с.

11. Скулов П.В. Повышение эффективности профессионально-методической подготовки учителя на основе принципа динамического баланса (на примере подготовки учителя физики): дис. ... канд. пед. наук. Барнаул, 2011. 327 с.

12. Антонова Н.А. Методическая подготовка студентов бакалавриата по направлению подготовки «Педагогическое образование» средствами экспериментальных задач // Актуальные проблемы развития среднего и высшего образования: межвуз. сб. науч. трудов / под ред. O.P. Шефер. Вып. XIV. Челябинск: Край Ра, 2018. С. 223-229.

13. Беленок И.Л. Теоретические основы профессионально-методической подготовки учителя в педа- гогическом вузе (на примере подготовки учителя физики): дис. ... д-ра пед. наук. Новосибирск, 2000. $345 \mathrm{c}$.

14. Карташова Н.С. Отбор содержания методической подготовки бакалавров естественнонаучного образования (профиль подготовки «Экология») // Университет XXI века: научное измерение: мат-лы науч. конф. профессорско-преподавательского состава, аспирантов, магистрантов и соискателей ТГПУ им. Л.Н. Толстого. Тула: Тульский государственный педагогический университет им. Л.Н. Толстого, 2011. C. $157-158$.

15. Махмудова Н., Кобилов В. Содержание научно-педагогических понятий «Методическая подготовка» и «Профессионально-методическая подготовка» учителя в научных исследованиях // Ученые записки Худжандского государственного университета им. академика Б. Гафурова. Серия гуманитарно-общественных наук. 2012. № 3 (31). С. 104-114.

16. Магомедов Р.М. О необходимости введения курса «Инновационные организационные формы обучения» в методическую подготовку учителя информатики // Информатика и образование. 2016. № 5 (274). C. 57-59.

17. Раисова А.М. Опытно-экспериментальная работа по реализации педагогических условий эффективного управления методической подготовкой будущего учителя в условиях университета // Наука и общество: проблемы современных исследований: XI междунар. науч.-практ. конф.: сб. статей в 2 ч. Ч. 1 / под ред. д-ра филол. наук, профессора А.Э. Еремеева. Омск: Изд-во ОмГА, 2017. С. 97-101.

18. Семенов А.А., Соловьева В.В., Яицкий А.С. Полифункциональная подготовка будущих учителей в контексте федеральных государственных образовательных стандартов и профессионального стандарта педагога // Самарский научный вестник. 2017. Т. 6, № 3 (20). С. 307-312.

19. Разаханова В.П., Борзова З.В. Применение интерактивных технологий в методической подготовке студентов-биологов в педагогическом вузе // Наука и образование: состояние, проблемы, перспективы развития: мат-лы науч. сессии профес.-преподават. состава Дагестан. гос. пед. ун-та, посв. 100-летию создания первого в Дагестане пед. ин-та. Махачкала: ДГПУ, 2018. С. 580-583.

20. Ахромушкина И.М., Валуева Т.Н. Из опыта использования интерактивных технологий в методической подготовке бакалавров направления подготовки «Химия» // Научно-методический электронный журнал «Концепт». 2015. Т. 34. С. 26-30.

\title{
MODERN FORMATS OF METHODICAL TRAINING OF STUDENTS MAJORING IN BIOLOGY
} (C) 2019

\author{
Mitina Elena Garisonovna, doctor of pedagogical sciences, associate professor, \\ professor of Natural Sciences Department \\ Kryshtop Victoria Anatolyevna, candidate of pedagogical sciences, \\ associate professor of Natural Sciences Department \\ Murmansk Arctic State University (Murmansk, Russian Federation)
}

Abstract. The paper is devoted to the study of students' attitude to the process of methodical training in high
school. The authors describe some examples of the «formatting» of the methodological training of biology students,
such as the «form of education», the «educational format», the «format of training» and others. The authors present
the analysis results of student survey about the preferences in choosing one format or another; the principles for the
inclusion of new formats in the learning process in higher education institutions were defined. The paper shows that,
at the present stage, the formats of methodical training, based on the direct interaction of all subjects of the educa-
tional process, are the most demanded ones by students, while learning formats on the Internet space are less attrac-
tive for respondents. The authors of the paper, on the basis of students' views study, found that the development of 
Митина Е.Г., Крыштоп В.А.

Современные форматы методической подготовки студентов-биологов

Педагогические науки

other subjects of the educational process and the continuous improvement of their qualifications are most important for the successful «formatting» of the methodological training of a teacher-biologist. The principles of new formats inclusion into the learning process presented by the authors in this paper focus it on expanding the boundaries of educational systems in accordance with modern trends in education the development, noted in new educational standards.

Keywords: form of training organization; training format; organizational forms and teaching methods; teacher training; methodical training; methodological training modules; educational environment; principles of formats inclusion; implementation of modern formats; internet space.

\title{
ИСПОЛЬЗОВАНИЕ ИНТЕГРАТИВНОГО ПОТЕНЦИАЛА ИНОСТРАННОГО ЯЗЫКА ПРИ ФОРМИРОВАНИИ ПРОФЕССИОНАЛЬНОЙ КОМПЕТЕНТНОСТИ БУДУЩЕГО АГРОНОМА В РЕАЛИЯХ ГЛОБАЛИЗАЦИИ
}

(C) 2019

\author{
Перькова Елена Леонидовна, кандидат педагогических наук, \\ доцент кафедры иностранных языков и гуманитарных наук \\ Никитина Светлана Вячеславовна, кандидат педагогических наук, \\ доцент кафедры иностранных языков и гуманитарных наук \\ Курская государственная сельскохозяйственная академия имени И.И. Иванова \\ (2. Курск, Российская Федерация)
}

\begin{abstract}
Аннотация. Данная статья посвящена проблеме формирования профессиональной компетентности в процессе изучения дисциплины «Иностранный язык» у студентов-бакалавров, выбравших направление подготовки «Агрономия». Авторы отмечают, что использование интегративного потенциала иностранного языка в современных реалиях является источником получения профессиональных знаний, передового опыта и подчеркивают, что владение иностранным языком дает возможность будущим агрономам свободно ориентироваться в профессиональной литературе, на рынке сельскохозяйственной продукции, а также в новейших технологиях, что ведет к повышению их конкурентоспособности в аграрной области. Таким образом, изучение иностранного языка помогает студенту-агроному совершенствовать профессиональную компетентность и мастерство, получить опыт работы за рубежом, узнать новую информацию. В связи с этим возникает потребность в пересмотре содержания, структуры, поиске новых подходов к организации процесса иноязычной подготовки будущих агрономов. В статье отмечается важность потенциала дисциплины «Иностранный язык» как интегративного фактора, влияющего на формирование профессиональной компетентности будущего агронома, и приводятся конкретные примеры его использования. Рассматриваются понятия «компетентность», «компетенция», «профессиональная компетентность будущего агронома» и анализируются взгляды отечественных и зарубежных ученых. Указывается целесообразность использования компетентностного подхода при формировании профессиональной компетентности, который в последнее время перерос рамки локальной теории и стал общественным явлением, которому отводится роль основной концепции развития образования. Положения статьи базируются на передовых изысканиях в области подготовки профессиональных кадров и преподавания иностранных языков.

Ключевые слова: иностранный язык; интегративный потенциал; компетентностный подход; бакалавры направления подготовки «Агрономия»; профессиональная компетентность; профессиональное общение; международное сотрудничество; сельское хозяйство; будущий агроном; аграрный бизнес; конкурентоспособность; зарубежные партнеры; образовательные онлайн-платформы; междисциплинарные связи.
\end{abstract}

В современных условиях глобализации иноязычная профессионально ориентированная подготовка студентов высшего сельскохозяйственного образования приобретает принципиальное значение. Иностранный язык становится одним из ведущих средств получения знаний и повышения профессиональной компетентности в сфере агрономии. В настоящее время иностранный язык является не только учебной дисциплиной, но «орудием производства» [1, с. 318], необходимым при подготовке профессионала нового формата: предприимчивого, способного к самообразовательной деятельности на протяжении всей своей карьеры, уважающего культуру, обычаи страны изучаемого языка и адекватно определяющего позиции родной культуры в мировом сообществе.

В век информационных технологий и новейших разработок, связанных с различными сферами дея- тельности, специалистам в любых областях, в том числе и сельскохозяйственной, важно быть компетентными и мобильными для того, чтобы оценить и проанализировать новаторские идеи, которые появляются в различных странах с целью использования в своей практической профессиональной деятельности. Работодатели повышают требования к профессиональной компетентности выпускников, а использование иностранного языка способствует решению задач в сфере сельского хозяйства. Обмен опытом между будущими специалистами сотрудничающих стран, заграничные практики, семинары не представляются без знания иностранного языка.

В нашей стране аграрный бизнес тесно связан с иностранными компаниями-поставщиками, покупателями, международными научными центрами и т.д. В деловых взаимоотношениях с зарубежными парт- 